\title{
GAIA Level 2 Preeclampsia with Severe
} Features

National Cancer Institute

\section{Source}

National Cancer Institute. GAIA Level 2 Preeclampsia with Severe Features. NCI

Thesaurus. Code C128007.

GAIA Level 2 Preeclampsia with Severe Features is defined by three criteria: first, the gestational age of the pregnancy must be greater than or equal to 20 weeks; second, a diagnosis of new onset maternal hypertension (systolic blood pressure greater than or equal to $140 \mathrm{mmHg}$ and/or diastolic blood pressure greater than or equal to $90 \mathrm{mmHg}$ ) that is sustained on two measurements for a minimum of one hour; third, the diagnosis of new onset nausea and vomiting. 